\title{
Physics and Piaget')
}

There will be a workshop leading up to the lectures of Professors Fuller and Piaget designed to introduce participants to the source of the basic principles of cognitive development that have flowed from Piaget's original ideas. No previous exposure to these ideas will be assumed. The workshops will give some appreciation of the kind of learning experiences that can help students progress in reasoning. A fee of $£$ 2-3 will be charged for the material employed.

Previous registration on the conference form is required for organizational reasons. The half-day parallel session on Wednesday morning devoted to Physics Education will be used to start the workshop. An opportunity for continuing at appropriate times will be given to the participants.

Why should people study physics? For a long time, physicists have advocated the importance of the study of physics, for a variety of reasons reasons that range from "physics is a part of our cultural heritage" to "physics is useful for repairing electrical appliances.

In the past decade a number of physicists have been brought into contact with the vast body of research conducted by Professor Jean Piaget, the noted Swiss psychologist. The work of Piaget seems to offer physicists a rationale for the study of physics and at the same time point to a radical transformation in many of the present methods of teaching.

Jean Piaget began his research on children in about 1920 , and the results of his work of primary interest to physicists are reported in the book The Growth of Logical Thinking from Childhood to Adolescence ${ }^{2}$ ). In this book the responses of young people to various tasks concerning physical phenomena are described. These tasks include such physics experiments as the equality of the angles of incidence and reflection, the law of floating bodies, the flexibility of metal rods, the oscillation of a pendulum, the motion of bodies on an inclined plane, the conservation of momentum on a horizontal plane, the equilibrium of a balance, and the projection of shadows.

On the basis of people's responses, Piaget and his co-workers developed a theory for interpreting the development of universal patterns of reasoning. Pivotal to this theory is the concept of stages of intellectual development. The stages are characterized by distinctive features in the patterns of a person's reasoning. It is hypothesized that each of Piaget's four stages serves as a precursor to all succeeding stages. and that reasoning develops sequentially, always from less effective to more effective, but not necessarily at the same rate for every individual.

Like a concept in any theory, a stage of intellectual development is a simplification which is helpful in analyzing and intepreting observations, somewhat like a point particle or a frictionless plane in mechanics. Thus, one must not expect that most people during their period of development will exhibit all the reasoning characteristics of, say, stage A for a certain period of time and then suddenly change to all the reasoning patterns appropriate to stage $B$. Rather, the development of a person's reasoning should be thought of as gradual. His or her reasoning on certain problems at a particular time may show the features of stage A while exhibiting certain features of stage B on others. The stage concept, therefore, may be more useful for classifying reasoning patterns than for describing the overall intellectual behaviour of a particular person at a given time.

The first Piagetian stage is called sensory-motor and is characteristic of children's thinking from birth to about two years of age. The next stage is the pre-operational stage and may last to about age eight. The third and fourth stages, concrete operations and formal operations, are of the greatest interest to physics teachers. Concrete reasoning enables a person to understand concepts and simple hypotheses that make direct reference to familiar actions and objects.

Formal reasoning patterns enable individuals to reason hypotheticodeductively. Such persons can accept an unproven hypothesis, deduce its consequences in the light of other known information, and then verify empirically whether those consequences, in fact, occur. In addition they can reflect upon their own reasoning to look for inconsistencies. They can check their results in numerical calculations against order-of-magnitude estimates. It is quite clear that a successful physics student makes use of formal reasoning. In fact, formal reasoning is a prerequisite for producing quality work in physics. issues relating to Piaget's work are still being investigated. Piaget's origi-
Many theoretical and experimental nal notion was that most persons use formal reasoning reliably by their late teens. Yet recent studies strongly suggest that, although almost everyone becomes able to use concrete reasoning, many adults do not come to use formal reasoning reliably. By applying memorized formulae, words or phrases, these persons often appear to be reasoning at the formal level and/or comprehending formal subject matter when they are, in fact, not doing so.

The development of formal reasoning represents an extremely worthwhile educational aim. Formal reasoning is fundamental to developing a meaningful understanding of mathematics, any science, and many other subjects of modern life. Therefore, the findings that more than one-third of the adolescents and adults do not employ formal reasoning patterns effectively presents a real educational challenge. What can be done about the significant fraction of the population that seems stuck at the stage of concrete reasoning?

We realize that physics as a profession benefits from a social and cultural milieu that fosters the development of formal reasoning patterns. In order to see in what sense physics may be an essential part of such a milieu, we need to consider another concept in Piaget's theory of intellectual development, that of selfregulation.

Self-regulation refers to the process whereby an individual's reasoning advances from one level to the next, an advance which is always from a less to a more integrated and better adapted level. Piaget views this process of intellectual development as analogous to the adaptation of evolving species. A person develops formal reasoning only through the process of self-regulation. Thus, concrete reasoning involving class inclusion, serial ordering, and conservation about real objects, events and situations is a prerequisite for the development of formal reasoning.

The process of self-regulation is one in which a person actively searches for relationships and patterns to resolve contradictions or bring coherence to a new set of experiences. Implicit in this notion is the image of a relatively autonomous person not under the constant guidance of a teacher or strict precedent.

The development of reasoning has two requirements: (1) exploratory 
experiences with the physical world, and (2) discussion and reflection upon what has been done, what it means, and how it fits or does not fit with previous patterns of thinking. This suggests that experiences gained through physics can play a key role in the development of reasoning and understanding. If physics is to be used to foster self-regulation, two factors seem to be required: (1) a physical situation that can be only partially understood in terms of old ideas and (2) sufficient time to grapple mentally with the new situation, possibly with appropriate hints but without being told the answer. Persons must be allowed to put their ideas together for themselves.

Two current modes of physics instruction seem to be at odds with Piaget's ideas. First, a physics lecture which is used to expound the general laws of physics before students have concrete experiences for understanding the laws is not likely to encourage self-regulation. Second, physics laboratory experiments designed to verify a known principle or experimental value such as $\mathrm{e} / \mathrm{m}$ or $\mathrm{g}$ probably do not develop reasoning.

Professor Piaget has indicated that the results of his research seem to call for far reaching reforms in education. Such reformed education would make "use of active methods which give broad scope to the spontaneous research of the adolescent and require that every new truth to be learned be rediscovered, or at least reconstructed, by the student, and not simply imparted to him" ${ }^{3}$ ).

Professor Piaget will address the Fourth General Conference of the European Physical Society on "Le développement psychologique de la physique chez l'enfant et l'adolescent". Other York activities will include a presentation on the implications of Piaget's work for physics teaching and the workshop on physics teaching and the development of reasoning referred to above.

\section{References}

1. This article is a summary of an article "Can Physics Develop Reasoning ?" by FULLER R.G., KARPLUS R. and LAWSON A.E., Physics Today 30 (2) (1977).

2. INHELDER B. and PIAGET J., The Growth of Logical Thinking from Childhood to Adolescence. (Basic Books, New York), 1958.

3. PIAGET J., To Understand is To Invent, The Future of Education (Penguin Books), 1976, p. 15.

\section{I.O.M. Delegates}

The new delegates to represent the Individual Ordinary Members on Council for a term of three years, replacing the retiring members: $J$. Diehl, L. Etienne-Amberg, I. Ursu and $\mathrm{H}$. van Regemorter are, as a result of the recent elections :

G. Eilenberger, Julich, D

J.P. Toennies, Göttingen, D

A. Janner, Nijmegen, NL

C. Hilsum, Gt. Malvern, UK

first alternate :

B. Levich, Moscow, USSR

\section{Bernard Gregory}

Members of EPS will all have been distressed to learn of the sudden death of Bernard Gregory on Dec. 25,1977 , at the age of 58. DirectorGeneral of CERN from 1966-70, Director of the French Centre National de la Recherche Scientifique from 1973-76 and since 1976, Délégué Général à la Recherche Scientifique and Technique (Europhysics News, 8, 7/8, p. 8), Gregory had just been appointed President of the CERN Council for 1978. $\mathrm{He}$ will be remembered in EPS for his keen interest in the establishment of the Society of which he was a founding member. He was host at the foundation meeting of the Society in Sept., 1968 and presided over the Steering Committee in Nov., 1966 when the fields of activity of the Society were defined and possible structures considered.

Europhysics News remembers him particularly for his offer to the Society, when it was divided on how best to establish a communication medium, of the services of CERN to create a bulletin on behalf of the Society. For many years Europhysics News was published from CERN and from these beginnings developed into the publication we have today. Europeans recall the lead he took in his own domain of high energy physics in fostering the collaboration between CERN and the high energy physics community of the eastern countries, by strengthening the ties with Dubna and then concluding in 1967, the agreement with the USSR State Committee for the Utilization of Atomic Energy, for the joint programme of research at Serpukhov.

French physicists are not alone in mourning the untimely death of one whose contribution to both physics and international understanding had already been so important and which R. G. Fuller held such promise for the future.

\section{Call for Nominations}

The EPS Selection Committee for the Hewlett-Packard Europhysics Prize (awarded annually for outstanding achievement in the field of solid state physics) will be pleased to consider for the 1979 award, candidates nominated by members of the Society.

The award is made in recognition of a recent work by one or more individuals in the area of physics of condensed matter, specifically work leading to advances in the fields of electronic, electrical and materials engineering which, in the opinion of the Society's selection committee, represents scientific excellence. "Recent work " is defined to mean completed within 5 years prior to the award. The award may be given for either pure or applied research at the discretion of the Society.

With any proposal, the committee needs, in addition to a clear definition of the work in question, a short biography of the candidate, a list of relevant publications and reprints of publications describing the work for which the award would be made. Such details should be sent to the committee c/o the Executive Secretary, at the EPS Secretariat to arrive not later than Dec. 1, 1978.

All information will be treated as confidential, but the Selection Committee wishes it to be understood that it cannot enter into correspondence over its selection.

\section{Member Societies}

New President of the Finnish Physical Society is Vesa Ruuskanen of the University of Jyväskylä.

New President of the Netherlands' Physical Society is Prof. P.R. Wyder of the University of Nijmegen.

New president of the Portuguese Physical Society is Prof. J. da Providência of the University of Coimbra.

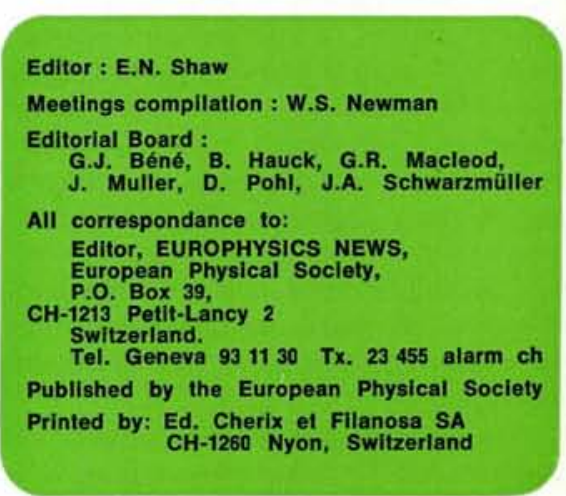

